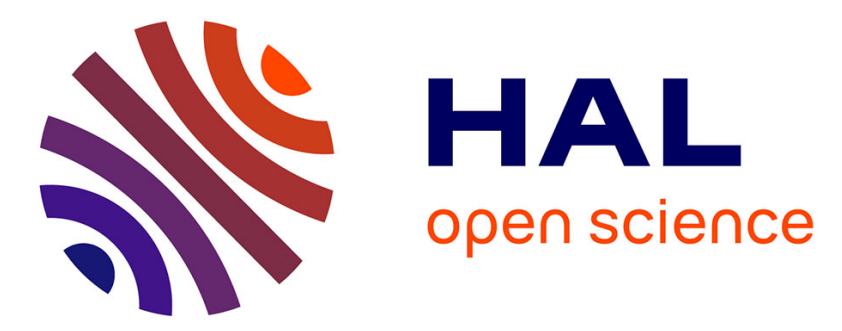

\title{
Markers of bone remodeling are associated with arterial stiffness in renal transplanted subjects
}

Anne-Sophie Bargnoux, Fernando Vetromile, Nils Kuster, Julie Barberet, Anne-Marie Dupuy, Jean Ribstein, Georges Mourad, Jean-Paul Cristol, Pierre Fesler

\section{To cite this version:}

Anne-Sophie Bargnoux, Fernando Vetromile, Nils Kuster, Julie Barberet, Anne-Marie Dupuy, et al.. Markers of bone remodeling are associated with arterial stiffness in renal transplanted subjects. Journal of Nephrology, 2015, 28 (6), pp.765-772. 10.1007/s40620-015-0201-5 . hal-01771947

\section{HAL Id: hal-01771947 \\ https://hal.umontpellier.fr/hal-01771947}

Submitted on 22 Jul 2018

HAL is a multi-disciplinary open access archive for the deposit and dissemination of scientific research documents, whether they are published or not. The documents may come from teaching and research institutions in France or abroad, or from public or private research centers.
L'archive ouverte pluridisciplinaire HAL, est destinée au dépôt et à la diffusion de documents scientifiques de niveau recherche, publiés ou non, émanant des établissements d'enseignement et de recherche français ou étrangers, des laboratoires publics ou privés. 


\title{
Markers of bone remodeling are associated with arterial stiffness in renal transplanted subjects
}

\author{
Anne-Sophie Bargnoux ${ }^{1,2} \cdot$ Fernando Vetromile $^{3} \cdot$ Nils Kuster $^{1,2} \cdot$ Julie Barberet $^{1} \cdot$

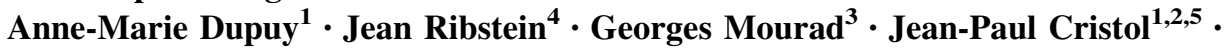 \\ Pierre Fesler ${ }^{4}$
}

\begin{abstract}
Background Bone-vessel interaction in chronic renal failure remains poorly understood and could be driven by bone remodeling factors including osteoprotegerin (OPG), fibroblast growth factor 23 (FGF23), parathormone and vitamin D. Only few data are available in renal transplantation. The aim of this study was to investigate the relationship between bone remodeling factors and large artery function in renal transplant patients.

Methods 89 renal transplant patients were enrolled in this cross-sectional study. Carotid to femoral pulse wave velocity (PWV) and central augmentation index (AIx) were determined as an estimation of large artery function. Blood samples were collected for measurement of vascular risk markers. Independent predictors were identified by multivariate linear regression through backward feature selection using Akaike's information criteria.

Results At multivariate analysis, age $(\mathrm{p}<0.001)$ and systolic arterial pressure $(\mathrm{p}=0.003)$ were significantly associated with PWV but not AIx. In addition, both

Jean-Paul Cristol

jp-cristol@chu-montpellier.fr

1 Laboratoire de Biochimie, CHRU Montpellier, Univ Montpellier 1, Montpellier, France

2 PhyMedExp, University of Montpellier, INSERM U1046, CNRS UMR 9214, 34295 Montpellier Cedex 5, France

3 Service de Néphrologie et Transplantation, CHRU Montpellier, Univ Montpellier 1, Montpellier, France

4 Service de Médecine Interne, CHRU Montpellier, Univ Montpellier 1, Montpellier, France

5 Department of Biochemistry, Lapeyronie University Hospital, 191 Avenue du Doyen Gaston Giraud, 34295 Montpellier Cedex 5, France
\end{abstract}

elevated blood concentrations of $1.25(\mathrm{OH})_{2}$ vitamin $\mathrm{D}$ $(\mathrm{p}=0.013)$ and OPG $(\mathrm{p}=0.047)$ were still significantly related to high $\mathrm{PWV}$.

Conclusions These results underline that age and mean arterial pressure are the main determinants of PWV following renal transplantation. Among bone remodeling biomarkers, plasma OPG and active vitamin D were the strongest determinants of arterial stiffness.

Keywords Arterial stiffness - Osteoprotegerin · Renal transplantation · Vitamin D

\section{Introduction}

Arterial stiffness, as measured by pulse wave velocity (PWV), is an important risk factor for cardiovascular events and has been recently identified as a strong predictor of all-cause mortality in kidney transplant patients [1]. Increased arterial stiffness has been associated with numerous traditional risk factors including age, blood pressure and diabetes [2] as well as with non traditional risk factors such as inflammation [3], albuminuria or reduced glomerular filtration rate (GFR) [4]. In addition, disorders of mineral and bone metabolism related to chronic kidney disease (CKD-MBD) [5] could contribute to the arterial remodeling and medial calcification leading to arterial stiffness with elevated pulse pressure (PP) and faster PWV [6]. Bone-vessel interaction in chronic renal failure could be driven by bone remodeling factors including osteoprotegerin (OPG), fibroblast growth factor 23 (FGF23), parathormone $(\mathrm{PTH})$ and vitamin $\mathrm{D}$. However, few data are available in renal transplantation. In renal transplant patients, PWV remains higher than in healthy subjects [7] 
despite restoration of renal function and thus elimination of toxins which have a role in promoting vascular remodeling.

The purpose of this study was therefore to evaluate the relationship between biomarkers of vascular risk (CKD, inflammation, malnutrition, mineral metabolism disorders and particularly bone disease markers such as OPG) and large artery function in renal transplant patients.

\section{Methods}

\section{Subjects}

Eighty-nine transplanted patients from the Montpellier university nephrology transplantation unit were enrolled in this cross-sectional study. As part of our regular patient follow-up and quality assurance process, the patients were admitted in the morning, after an overnight fast, to our outpatient clinic for renal hemodynamic and function tests. All reported investigations were carried out in accordance with the principles of the Declaration of Helsinki as revised in 2000 (http://www.wma.net/e/poling/17-ce.html); informed consent was obtained from all patients before participating in the study. In accordance with French law, the study was registered at the Ministère de l'Enseignement Supérieur et de la Recherche with the number DC-2008417 after it was approved by our institution's ethical committee.

\section{Clinical evaluation}

Detailed medical history including age, gender, weight, height, cause of CKD, time spent in dialysis, diabetes mellitus, hypertension, immunosuppressive regimen, medications (vitamin D, phosphate binders, calcimimetics), and presence of atherosclerotic cardiovascular disease was recorded. Existence of hypertension was defined by brachial blood pressure higher than or equal to $140 / 90 \mathrm{mmHg}$ and/or by current antihypertensive treatment. Presence of atherosclerotic cardiovascular disease was defined by the presence of at least one of the three following manifestations: coronary heart disease, cerebrovascular disease, and peripheral atherosclerotic disease [8].

\section{Determination of renal function}

Glomerular filtration rate was measured by urinary clearance of technetium-labeled diethylene-triamino-pentaacetic acid $\left.{ }^{99 \mathrm{~m}} \mathrm{Tc}-\mathrm{DTPA}\right)$ using the constant infusion technique, as previously described [9]. Briefly, after the induction of water diuresis and a 90-min equilibration period, four 20- to 30-min urine collections were obtained by spontaneous voiding. At midpoint of each clearance period, blood was drawn for the determination of plasma radioactivity and hematocrit. The measured GFR (mGFR) value was the average of four measurements.

\section{Blood pressure measurements}

In strictly standardized conditions, arterial pressure was measured in the supine position, after a 10-min period of rest every 3-5 min with an automatic device (Dinamap 845 XT, Critikon, Chatenay Malabry, France). The value used in this study was the average of the mean values obtained during the four clearance periods. Pulse pressure (PP) was considered as the difference between the systolic and the diastolic blood pressure (SBP and DBP), and mean arterial pressure (MAP) was calculated by the formula $\mathrm{MAP}=(\mathrm{SBP}+2 \mathrm{DBP}) / 3[9]$.

\section{Pulse wave velocity}

Femoral, carotid and radial pressure waveforms were recorded by applanation tonometry using the SphygmoCor system (AtCor Medical, Sydney, Australia). From carotid and femoral waveforms, wave transit time was calculated using the $\mathrm{R}$ wave of a simultaneously recorded electrocardiogram as a reference frame and the foot of the waves determined with intersecting tangent algorithm. Transit distance was calculated as $80 \%$ of the direct carotidfemoral distance and carotid-femoral PWV was calculated as transit distance divided by transit time [10].

\section{Pulse wave analysis}

The central aortic waveform and the augmentation index (AIx) were derived by applying a validated transfer function to recordings of the arterial pressure waves at the radial artery. The AIx was calculated as augmented pressure/central pulse pressure.

\section{Laboratory measurements}

While patients were in the supine position and before the start of GFR measurement, blood samples were collected and centrifuged for routine parameter measurements, then the remaining supernatant was stored at $-80{ }^{\circ} \mathrm{C}$ for later processing of FGF23 and OPG. Enzymatic creatinine and high-sensitivity C-reactive protein (hs-CRP) were measured using Randox reagents (Randox, Mauguio, France) on an Olympus apparatus (Olympus, Rungis, France). Plasma glucose, albumin, calcium and phosphate were assessed on an Olympus apparatus. Serum total cholesterol (TC), highdensity lipoprotein cholesterol (HDL) and triglyceride (TG) levels were measured by an enzymatic method (Architect; Abbott Park, IL, USA). Glycohemoglobin (Hba1c) was 
measured by the HPLC method (HA $8140^{\circledR}$; Menarini Diagnostic, Rungis, France). The ratio of urinary concentration of albumin (immunoturbidimetric method) and creatinine (Jaffe method) was calculated as a surrogate measurement of the albumin excretion rate [albumin to creatinine ratio (ACR) in $\mathrm{mg} / \mathrm{mmol}] .25(\mathrm{OH})$ vitamin $\mathrm{D}$ and $1.25(\mathrm{OH})_{2}$ vitamin $\mathrm{D}$ were measured by radioimmunoassay (Immunodiagnostic Systems, Boldon, UK). Intact PTH was measured by immunoradiometric assay (N-Tact PTH SP IRMA Kit, DiaSorin, Stillwater, MN, USA). Serum OPG was determined by enzyme-linked immunosorbent assay (ELISA) (MicroVue OPG kit; Quidel, San Diego, CA, USA). Plasma FGF23 was measured with an ELISA detecting both intact FGF23 and C-terminal fragments (Immutopics International Inc., San Clemente, CA, USA).

\section{Statistical analysis}

Continuous data are reported as median and interquartile range (IQR) and categorical data as percentage for descriptive purposes. Since the distribution of PWV values in our population was skewed, logarithmic transformation (base 2) was used for PWV values prior to modeling. Predictors of PWV were identified using least squares linear regression. Covariates significantly associated with PWV at the 0.15 level after adjustment for age and gender were proposed for multivariate analysis. For multivariate model building, a backward automated variable selection procedure based on the Akaike information criterion (AIC) was used. Significance level was set to $p<0.05$. Statistical analysis was performed using R 2.15 software (R Foundation for Statistical Computing, Vienna, Austria).

\section{Results}

\section{Baseline characteristics}

Clinical and biological characteristics of the 89 renal transplant patients at baseline are reported in Table 1. The median age was 51 years and the gender ratio was 1.96 (59 males/30 females). CKD causes were as follows: glomerulonephritis $(\mathrm{n}=15)$, polycystic kidney disease $(\mathrm{n}=18)$, diabetic nephropathy $(\mathrm{n}=2)$, hypertensive nephropathy $(\mathrm{n}=2)$, unknown cause $(\mathrm{n}=21)$ and other $(\mathrm{n}=31)$. Most patients were hypertensive, few diabetics were included, and half of the group never smoked. Past history of cardiovascular disease was found in 1 in 5 patients. Median time since transplantation was 1 year (IQR 3.4-12.1 months). Immunosuppressive protocols included a sequential quadruple therapy regimen. On the day of
Table 1 Characteristics of transplant patients at baseline $(n=89)$

\begin{tabular}{|c|c|}
\hline Parameter & Value \\
\hline Gender, male $(\%)$ & 66.3 \\
\hline Age (years) & $50.6(40.6-60.3)$ \\
\hline Body mass index $\left(\mathrm{kg} / \mathrm{m}^{2}\right)$ & $23.8(21.4-25.5)$ \\
\hline Time spent in dialysis (months) & $27(8-43)$ \\
\hline Smoking status (\% of never smoked) & $53.9 \%$ \\
\hline Diabetes mellitus & $9 \%$ \\
\hline Hypertension & $89.9 \%$ \\
\hline History of cardiovascular disease & $22.5 \%$ \\
\hline Cold ischemia time (min) & $1080(832-1352)$ \\
\hline Delayed graft function (\%) & 12.4 \\
\hline Rejection episodes (\%) & 13.5 \\
\hline Systolic blood pressure (mmHg) & $128(120-136)$ \\
\hline Diastolic blood pressure $(\mathrm{mmHg})$ & $75(70-82)$ \\
\hline Mean arterial pressure $(\mathrm{mmHg})$ & $93(88-100)$ \\
\hline Arterial pulse pressure $(\mathrm{mmHg})$ & $53(45-60)$ \\
\hline Pulse wave velocity, PWV (m/s) & $8.3(7.4-9.1)$ \\
\hline Augmentation index, AIx (\%) & $24(16-32)$ \\
\hline Glomerular filtration rate $\left(\mathrm{ml} / \mathrm{min} / 1.73 \mathrm{~m}^{2}\right)$ & $57.3(43.2-68.8)$ \\
\hline Albumin to creatinine ratio, ACR $(\mathrm{mg} / \mathrm{mmol})$ & $1.7(0.9-4.1)$ \\
\hline Total cholesterol $(\mathrm{mmol} / \mathrm{l})$ & $5.34(4.57-6.07)$ \\
\hline Non HDL cholesterol (mmol/l) & $3.88(3.22-4.75)$ \\
\hline C-reactive protein $(\mathrm{mg} / \mathrm{l})$ & $1.3(0.6-2.8)$ \\
\hline Glycemia (mmol/l) & $5.3(4.8-5.7)$ \\
\hline Glycohemoglobin, Hba1c (\%) & $5.8(5.3-6.1)$ \\
\hline Albumin (g/l) & $44(42-45)$ \\
\hline Corrected calcium (mmol/l) & $2.48(2.43-2.56)$ \\
\hline Phosphorus (mmol/l) & $0.83(0.71-0.93)$ \\
\hline Parathyroid hormone (pg/ml) & $72(47-120)$ \\
\hline $1.25(\mathrm{OH})_{2}$ vitamin $\mathrm{D}(\mathrm{pg} / \mathrm{ml})$ & $52(40-68)$ \\
\hline $25(\mathrm{OH})$ vitamin $\mathrm{D}(\mathrm{ng} / \mathrm{ml})$ & $22.9(17.2-29.5)$ \\
\hline Osteoprotegerin (pmol/l) & $4.4(3-5.9)$ \\
\hline FGF23 (RU/ml) & $116(89-153)$ \\
\hline \multicolumn{2}{|l|}{ Medications } \\
\hline Vitamin D & $53.9 \%$ \\
\hline Calcium-based phosphate binders & $3.4 \%$ \\
\hline Calcimimetics & $4.5 \%$ \\
\hline
\end{tabular}

Values are described as proportions for categorical variables and median (interquartile range) for quantitative variables

$H D L$ high-density lipoprotein

inclusion, maintenance immunosuppression was as follows: $92.1 \%$ of patients were on calcineurin inhibitors ( $29.2 \%$ cyclosporine and $62.9 \%$ tacrolimus), $7.9 \%$ were on mammalian target of rapamycin (mTOR) inhibitors (sirolimus/everolimus), $92.1 \%$ on mycophenolic acid compounds, $4.5 \%$ on azathioprine, and $30.3 \%$ were steroid free. 


\section{Determinants of artery function}

Older age was significantly associated with higher PWV and AIx ( $\mathrm{p}<0.001$ for both). Gender was significantly associated with higher AIx $(\mathrm{p}<0.01)$ but not PWV $(p=0.095)$. After adjustment for these two variables (Table 2$)$, systolic BP $(\mathrm{p}=0.002)$, MAP $(\mathrm{p}=0.018)$ and PP $(p=0.046)$ were significantly associated with higher PWV but not smoking habit $(\mathrm{p}=0.413)$, diabetes mellitus $(\mathrm{p}=0.801)$, time since transplantation $(\mathrm{p}=0.843)$, time spent on dialysis prior to transplantation $(\mathrm{p}=0.721)$, mGFR $(\mathrm{p}=0.193)$, vitamin D therapy $(\mathrm{p}=0.22)$ or history of cardiovascular disease $(\mathrm{p}=0.477)$ in our population. Among the biomarkers of vascular risk studied, age-sex adjusted logistic regression analysis clearly identified high OPG $(\mathrm{p}=0.017)$, high $1.25(\mathrm{OH})_{2}$ vitamin $\mathrm{D}$ $(\mathrm{p}=0.007)$ and elevated CRP $(\mathrm{p}=0.048)$ as the only variables associated with increased PWV (Table 2). By contrast, no significant relationship between PWV and calcium $(\mathrm{p}=0.939)$, phosphorus $(\mathrm{p}=0.35), \quad$ FGF23 $(\mathrm{p}=0.523), \quad$ PTH $(\mathrm{p}=0.503)$ or $25(\mathrm{OH})$ vitamin $\mathrm{D}$ $(p=0.874)$ was observed. In addition, no relationship was found between AIx and the studied parameters (data not shown).

A multivariate linear regression analysis was carried out to identify independent predictors of PWV. The model
Table 2 Predictors of $\log$ transformed pulse wave velocity

\begin{tabular}{|c|c|c|}
\hline Parameter & Beta coefficient & $\mathrm{p}$ value \\
\hline Age (years) & $0.012(0.008$ to 0.016$)$ & $<0.001$ \\
\hline Gender (female) & $0.109(-0.21$ to 0.239$)$ & 0.105 \\
\hline Body mass index $\left(\mathrm{kg} / \mathrm{m}^{2}\right)$ & $-0.008(-0.024$ to 0.007$)$ & 0.293 \\
\hline Time spent in dialysis (months) & $0(-0.002$ to 0.003$)$ & 0.721 \\
\hline Time since transplantation (months) & $0.001(-0.011$ to 0.013$)$ & 0.843 \\
\hline Smoking status (yes) & $-0.047(-0.159$ to 0.065$)$ & 0.413 \\
\hline Diabetes mellitus & $-0.025(-0.216$ to 0.167$)$ & 0.801 \\
\hline History of cardiovascular disease & $0.049(-0.086$ to 0.184$)$ & 0.477 \\
\hline Cold ischemia time (min) & $-0.003(-0.01$ to 0.004$)$ & 0.383 \\
\hline Delayed graft function (\%) & $0.055(-0.108$ to 0.218$)$ & 0.511 \\
\hline Rejection episodes (\%) & $-0.053(-0.211$ to 0.105$)$ & 0.513 \\
\hline Systolic blood pressure (mmHg) & $0.008(0.003$ to 0.012$)$ & 0.002 \\
\hline Diastolic blood pressure $(\mathrm{mmHg})$ & $0.004(-0.002$ to 0.01$)$ & 0.194 \\
\hline Mean arterial pressure $(\mathrm{mmHg})$ & $0.008(0.002$ to 0.015$)$ & 0.018 \\
\hline Arterial pulse pressure $(\mathrm{mmHg})$ & $0.005(0$ to 0.01$)$ & 0.046 \\
\hline Glomerular filtration rate $\left(\mathrm{ml} / \mathrm{min} / 1.73 \mathrm{~m}^{2}\right)$ & $0.002(-0.001$ to 0.005$)$ & 0.193 \\
\hline Albumin to creatinine ratio, $\mathrm{ACR}(\mathrm{mg} / \mathrm{mmol})$ & $003(-0.001$ to 0.008$)$ & 0.180 \\
\hline Total cholesterol (mmol/l) & $0.016(-0.023$ to 0.056$)$ & 0.419 \\
\hline Non HDL cholesterol (mmol/l) & $0.023(-0.018$ to 0.064$)$ & 0.278 \\
\hline Log C-reactive protein (mg/l) & $0.032(0.001$ to 0.063$)$ & 0.048 \\
\hline Glycemia (mmol/l) & $0.009(-0.056$ to 0.075$)$ & 0.784 \\
\hline Glycohemoglobin, Hba1c (\%) & $-0.056(-0.142$ to 0.03$)$ & 0.204 \\
\hline Albumin (g/l) & $0.012(-0.008$ to 0.032$)$ & 0.232 \\
\hline Corrected calcium (mmol/l) & $0.012(-0.29$ to 0.314$)$ & 0.939 \\
\hline Phosphorus (mmol/l) & $-0.119(-0.368$ to 0.129$)$ & 0.35 \\
\hline Parathyroid hormone (pg/ml) & $0(-0.001$ to 0.001$)$ & 0.503 \\
\hline $1.25(\mathrm{OH})_{2}$ vitamin $\mathrm{D}(\mathrm{pg} / \mathrm{ml})$ & $0.003(0.001$ to 0.005$)$ & 0.007 \\
\hline $25(\mathrm{OH})$ vitamin $\mathrm{D}(\mathrm{ng} / \mathrm{ml})$ & $0(-0.005$ to 0.006$)$ & 0.874 \\
\hline Osteoprotegerin (pmol/l) & $0.042(0.008$ to 0.075$)$ & 0.017 \\
\hline Log FGF23 (RU/ml) & $-0.023(-0.093$ to 0.047$)$ & 0.523 \\
\hline Cyclosporine & $-0.109(-0.225$ to 0.008$)$ & 0.07 \\
\hline Tacrolimus & $0.077(-0.033$ to 0.187$)$ & 0.174 \\
\hline Sirolimus/everolimus & $0.06(-0.139$ to 0.259$)$ & 0.556 \\
\hline Medications with vitamin D & $-0.068(-0.174$ to 0.039$)$ & 0.217 \\
\hline
\end{tabular}

Bold values indicate significant $\mathrm{p}$ value

$H D L$ high-density lipoprotein 
Table 3 Predictors of logtransformed pulse wave velocity at multivariate analysis

\begin{tabular}{lcr}
\hline Parameter & Beta coefficient & p value $^{\mathrm{a}}$ \\
\hline Age $($ years $)$ & $0.009(0.005$ to 0.014$)$ & $<0.001$ \\
$1.25(\mathrm{OH})_{2}$ vitamin D $(\mathrm{pg} / \mathrm{ml})$ & $0.002(0.001$ to 0.004$)$ & 0.013 \\
Osteoprotegerin $(\mathrm{pmol} / \mathrm{l})$ & $0.033(0.001$ to 0.064$)$ & 0.047 \\
Systolic blood pressure $(\mathrm{mmHg})$ & $0.007(0.003$ to 0.012$)$ & 0.003 \\
Cyclosporine treatment & $-0.112(-0.218$ to -0.006$)$ & 0.041 \\
\hline
\end{tabular}

$m G F R$ measured glomerular filtration rate

a Adjustment for gender, diabetes, mGFR, and time spent in dialysis prior to transplantation included all variables with a $\mathrm{p}$ value $<0.15$ in the univariate analysis as potential candidates and was further adjusted for variables known to influence arterial stiffness (diabetes, mGFR, time spent in dialysis prior to transplantation) (Table 3). At multivariate analyses, age $(\mathrm{p}<0.001)$ and systolic arterial pressure $(\mathrm{p}=0.003)$ remained significantly associated with PWV values, along with immunosuppressive treatment (cyclosporine, $\mathrm{p}=0.041$ ). In addition, both elevated blood concentrations of $1.25(\mathrm{OH})_{2}$ vitamin $\mathrm{D}(\mathrm{p}=0.013)$ and $\mathrm{OPG}(\mathrm{p}=0.047)$ were still significantly related to high PWV.

\section{Discussion}

In the present study involving renal transplant recipients, the relationship between established as well as newly proposed biomarkers of vascular risk and the extent of arterial stiffness based on PWV was evaluated. As reported in numerous other clinical conditions, age and blood pressure were found to be strong determinants of arterial stiffness in renal transplantation $[2,6]$. We extended these findings by demonstrating that PWV was also independently related to bone remodeling biomarkers such as OPG and $1.25(\mathrm{OH})_{2}$ vitamin $\mathrm{D}$.

Cardiovascular disease (CVD) is the leading cause of death in renal transplant patients. Since traditional risk factors may not solely explain the excess risk of CVD, this may suggest another pathophysiology in these populations. Medial arterial calcification (MAC) is recognized to cause arterial stiffness and subsequently could contribute to cardiovascular morbidity and mortality [11]. MAC is mainly associated with CKD-induced mineral metabolism disorders but also with age and diabetes. However, we did not observe any association between diabetes mellitus or CKD stages and PWV in our study. At univariate analysis, median PWV was similar in non-diabetics [8.21 $(7.39-9.13) \mathrm{m} / \mathrm{s}$ ] and diabetic transplanted patients $[8.42$ $(8.00-9.42) \mathrm{m} / \mathrm{s}](\mathrm{p}=0.32$, Wilcoxon test). In addition, only a non-significant trend was observed between CKD stages progression and PWV [7.77 (7.17-8.67) for CKD stages I-II, 8.32 (7.38-9.62) for CKD stage IIIA, 8.63
(7.96-9.87) for CKD stage IIIB, and $8.59(8.46-10.25)$ for CKD stages IV-V; $\mathrm{p}=0.14$, Kruskal-Wallis test]. The absence of any relationship between diabetes or CKD stages and PWV in the present study may be related to the fact that only $10 \%$ of the study population had diabetes and that the majority had only moderate impairment in kidney functions (59\% with stage III CKD; $60 \%$ with ACR $<3 \mathrm{mg} / \mathrm{mmol}$ ). Indeed, the previously observed weak relationship between renal impairment and arterial stiffness could have been attenuated by the narrow range of renal function in our study $[4,12]$. Inflammation was shown to be associated with increased arterial stiffness [4]. However, the relationship observed at univariate analysis between low grade inflammation and PWV did not reach significance at multivariate analysis. Here again, it should be noted that CRP distribution was quite similar to that of healthy volunteers [13] and that the evaluation of low grade inflammation was altered by active immunosuppression.

Arterial stiffness has been reported to be dependent on the immunosuppressive protocol but the association remains unclear. Strózecki et al. [14] established that use of cyclosporine in kidney transplant recipients leads to increased PWV compared to a tacrolimus-based immunosuppressive protocol. Conversely, in the present study, a close to significant negative association was observed between PWV and cyclosporine. This difference could be partly explained by a shorter transplant follow-up (median time 1 vs. $>2$ years) and a higher proportion of patients under tacrolimus (63 vs. $43 \%$ ) compared to Strózecki et al. [14]. Of note, cyclosporine has been previously associated with a lower incidence of glucose abnormalities and use of hypoglycemic medication than tacrolimus at 6 months post-transplantation, both conditions related to increased arterial stiffness [15].

Abnormalities of bone and mineral metabolism have been recognized as an important component of arterial dysfunction in CKD patients [11, 16, 17]. However, the intricacy of mechanisms involved in arterial stiffness development between vitamin $\mathrm{D}$, secondary hyperparathyroidism, FGF23, bone remodeling regulators such as OPG/ receptor activator of NF-B ligand (RANKL) and Wnt/ LRP5/sclerostin remain poorly understood [18] and could 
be further complicated by the use of calcineurin inhibitors in the context of post-transplantation bone disease. Contrary to previous observations in CKD patients $[5,19]$, we did not find any relationship between $25(\mathrm{OH})$ vitamin D and PWV in the present study, but a clear, independent and positive association between $1.25(\mathrm{OH})_{2}$ vitamin $\mathrm{D}$ and PWV. It is noteworthy that in dialysis children a U-shaped curve has been evidenced between active vitamin D and vascular calcification [20]. In addition, data from human studies and animal models suggest a biphasic cardiovascular effect of active vitamin D [21] which could be partly related to FGF23 action on 1-alpha and 1-24 hydroxylase.

The level of FGF23 rises as renal function declines [22] and reaches maximal values in dialysis patients. FGF23 remains elevated for some months after renal transplantation as compared with subjects of similar GFR and diminishes after 1 year [23]. Several studies have reported an association between FGF23 and endothelial dysfunction, vascular calcifications, arterial stiffness and/or outcome in CKD and dialysis patients [24, 25] via Klotho-dependent or independent pathways. However a recent study by Scialla et al. [26] has challenged this point of view. In this translational study including 1,501 CKD patients, no relationship was found between FGF23 and arterial calcification. These features have been recently confirmed in hemodialysis patients [27]. Our results are in agreement with these observations and previous data from our group suggesting that, in a cohort of CKD stage I to V, FGF23 was associated with high, not moderate, calcification, in contrast to OPG [22].

Evidence supports the assumption that the OPG/ RANKL complex cytokine network, a key factor in the regulation of bone metabolism, may be expressed and implicated in vascular pathophysiology. Indeed, OPG has been proposed as a protective factor for vascular calcium deposition regarding data from animal models [28]. However, epidemiological studies [29] support the notion that elevated levels of OPG are associated with vascular risk in both general and high-risk populations including CKD patients. We previously demonstrated that OPG was a strong predictor of coronary artery calcification during the progression of CKD as well as during dialysis [8, 22]. In agreement with results in CKD [30] and dialysis patients [31], OPG is shown to predict PWV in post-transplant renal patients. In this context, it may be questioned whether an increase in OPG level represents a deleterious effect of OPG in the vascular calcification process or a compensatory self-defensive mechanism against factors that promote vascular calcification. Indeed, elevation of OPG levels in response to vascular calcification could block the bone remodeling process in vascular tissue through binding to RANKL and neutralize the pro-apoptotic actions of tumor necrosis factor (TNF)-related apoptosis-inducing ligand (TRAIL) [32]. Alternatively, it has been reported that OPG exhibits some potential effects that may contribute to vascular injury [33]. For example, it has been shown that treatment of apolipoprotein E (ApoE)-deficient mice with recombinant OPG resulted in an increased collagen content of the vascular media [34]. Excess synthesis of bone extracellular matrix by osteoblasts could lead to arterial stiffness without any mineralization. In addition, OPG could modulate inflammation and endothelial dysfunction [28].

The largest studies on evolution of vascular calcification after renal transplantation show that renal transplantation slows but does not halt the progression of both coronary (CAC) and aortic calcification (AoC) compared to what observed in hemodialysis [11]. In line with these data, we have previously shown, in a cohort of 76 patients, that the CAC score progressed in $26.3 \%$ of patients 1 year after renal transplantation [8]. Interestingly, we observed in the "non-progression" group, a subgroup of patients (14.5\%) who had a reduction in CAC score, and the pre-transplant level of OPG predicted in part progression of calcification after renal transplantation [8]. Since OPG has been associated with progression of vascular calcification, it may be questioned whether normalization of $\mathrm{OPG}$, as one of the promotors of MAC, cannot be associated with regression of pre-existing calcification. However, given the relatively short period of time for follow-up post-transplant, it may be difficult to draw conclusions about the reversibility, and long-term follow-up is needed. Circulating OPG may also reflect a new balance between bone turn-over and vascular production which could be affected by immunosuppression $[35,36]$. However, no data are currently available concerning the relative action of cyclosporine and tacrolimus on the OPG/RANKL system.

Our study has some limitations. Firstly, the relatively small sample size of this cross-sectional study may have prevented some associations from being statistically significant. Secondly, known risk factors of MAC leading to arterial stiffness, e.g. diabetes, and advanced CKD stages, were not adequately represented in our population, which may have attenuated the associations. Finally, FGF23 and OPG were analyzed as biomarkers but their pathophysiological role could not be evaluated without an assessment of their corresponding receptor/ligand Klotho or RANKL.

\section{Conclusion}

In conclusion, we have demonstrated that OPG and active vitamin D are associated with arterial stiffness in the early post-transplant period following renal transplantation. This complex relationship with bone-vascular disease in kidney recipients remains incompletely understood, since it 
probably involves renal and extra-renal factors such as inflammation, immunosuppressive regimens, preexisting bone disease and vascular calcifications.

Conflict of interest On behalf of all authors, the corresponding author states that there is no conflict of interest.

Informed consent Informed consent was obtained from all individual participants included in the study.

Research involving human participants All procedures performed in studies involving human participants were in accordance with the ethical standards of the institutional and/or national research committee and with the 1964 Helsinki declaration and its later amendments or comparable ethical standards.

\section{References}

1. Mitchell A, Opazo Saez A, Kos M, Witzke O, Kribben A, Nürnberger J (2010) Pulse wave velocity predicts mortality in renal transplant patients. Eur J Med Res 15:452-455

2. Reference Values for Arterial Stiffness' Collaboration (2010) Determinants of pulse wave velocity in healthy people and in the presence of cardiovascular risk factors: 'establishing normal and reference values'. Eur Heart J 31:2338-2350

3. Yasmin McEniery CM, Wallace S, Mackenzie IS, Cockcroft JR, Wilkinson IB (2004) C-reactive protein is associated with arterial stiffness in apparently healthy individuals. Arterioscler Thromb Vasc Biol 24:969-974

4. Hermans MM, Henry R, Dekker JM et al (2007) Estimated glomerular filtration rate and urinary albumin excretion are independently associated with greater arterial stiffness: the Hoorn Study. J Am Soc Nephrol 18:1942-1952

5. London GM, Guérin AP, Verbeke FH et al (2007) Mineral metabolism and arterial functions in end-stage renal disease: potential role of 25-hydroxyvitamin D deficiency. J Am Soc Nephrol 18:613-620

6. Briet M, Boutouyrie P, Laurent S, London GM (2012) Arterial stiffness and pulse pressure in CKD and ESRD. Kidney Int 82:388-400

7. Verbeke F, Van Biesen W, Peeters P, Van Bortel LM, Vanholder RC (2007) Arterial stiffness and wave reflections in renal transplant recipients. Nephrol Dial Transplant 22:3021-3027

8. Bargnoux AS, Dupuy AM, Garrigue V et al (2009) Evolution of coronary artery calcifications following kidney transplantation: relationship with osteoprotegerin levels. Am J Transplant 9:2571-2579

9. Vetromile F, Szwarc I, Garrigue V et al (2009) Early high pulse pressure is associated with graft dysfunction and predicts poor kidney allograft survival. Transplantation 88:1088-1094

10. Van Bortel LM, Laurent S, Boutouyrie P et al (2012) Expert consensus document on the measurement of aortic stiffness in daily practice using carotid-femoral pulse wave velocity. J Hypertens 30:445-448

11. Cianciolo G, Capelli I, Angelini ML et al (2014) Importance of vascular calcification in kidney transplant recipients. Am J Nephrol 39:418-426

12. Sengstock D, Sands RL, Gillespie BW et al (2010) Dominance of traditional cardiovascular risk factors over renal function in predicting arterial stiffness in subjects with chronic kidney disease. Nephrol Dial Transplant 25:853-861

13. Delcourt C, Dupuy AM, Carriere I, Lacroux A, Cristol JP, Pathologies OculairesLiées à l'Age study group (2005) Albumin and transthyretin as risk factors for cataract: the POLA study. Arch Ophthalmol 123:225-232

14. Strózecki P, Adamowicz A, Włodarczyk Z, Manitius J (2010) Factors associated with increased arterial stiffness in renal transplant recipients. Med Sci Monit 16:301-306

15. Vincenti F, Friman S, Scheuermann E et al (2007) Results of an international, randomized trial comparing glucose metabolism disorders and outcome with cyclosporine versus tacrolimus. Am J Transplant 7:1506-1514

16. Savica V, Bellinghieri G, Monardo P, Muraca U, Santoro D (2013) An update on calcium metabolism alterations and cardiovascular risk in patients with chronic kidney disease: questions, myths and facts. J Nephrol 26:456-464

17. Cannata-Andía JB, Rodriguez García M, Gómez Alonso C (2013) Osteoporosis and adynamic bone in chronic kidney disease. J Nephrol 26:73-80

18. Evenepoel P, Rodriguez M, Ketteler M (2014) Laboratory abnormalities in CKD-MBD: markers, predictors, or mediators of disease? Semin Nephrol 34:151-163

19. Chitalia N, Recio-Mayoral A, Kaski JC, Banerjee D (2012) Vitamin D deficiency and endothelial dysfunction in non-dialysis chronic kidney disease patients. Atherosclerosis 220:265-268

20. Shroff R, Egerton M, Bridel M et al (2008) A bimodal association of vitamin D levels and vascular disease in children on dialysis. J Am Soc Nephrol 19:1239-1246

21. Razzaque MS (2011) The dualistic role of vitamin D in vascular calcifications. Kidney Int 79:708-714

22. Morena M, Jaussent I, Halkovich A et al (2012) Bone biomarkers help grading severity of coronary calcifications in non dialysis chronic kidney disease patients. PLoS ONE 7:e36175

23. Evenepoel P, Meijers BK, de Jonge H et al (2008) Recovery of hyperphosphatoninism and renal phosphorus wasting one year after successful renal transplantation. Clin J Am Soc Nephrol 3:1829-1836

24. Gutiérrez OM, Januzzi JL, Isakova T et al (2009) Fibroblast growth factor 23 and left ventricular hypertrophy in chronic kidney disease. Circulation 119:2545-2552

25. Yilmaz MI, Sonmez A, Saglam M et al (2010) FGF-23 and vascular dysfunction in patients with stage 3 and 4 chronic kidney disease. Kidney Int 78:679-685

26. Scialla JJ, Lau WL, Reilly MP et al (2013) Fibroblast growth factor 23 is not associated with and does not induce arterial calcification. Kidney Int 83:1159-1168

27. Lee CT, Chua S, Hsu CY et al (2013) Biomarkers associated with vascular and valvular calcification in chronic hemodialysis patients. Dis Markers 34:229-235

28. Doherty TM, Fitzpatrick LA, Inoue D et al (2004) Molecular, endocrine, and genetic mechanisms of arterial calcification. Endocr Rev 25:629-672

29. Nybo M, Rasmussen LM (2008) The capability of plasma osteoprotegerin as a predictor of cardiovascular disease: a systematic literature review. Eur J Endocrinol 159:603-608

30. Scialla JJ, Leonard MB, Townsend RR et al (2011) Correlates of osteoprotegerin and association with aortic pulse wave velocity in patients with chronic kidney disease. Clin J Am Soc Nephrol 6:2612-2619

31. Speer G, Fekete BC, El Hadj Othmane T et al (2008) Serum osteoprotegerin level, carotid-femoral pulse wave velocity and cardiovascular survival in haemodialysis patients. Nephrol Dial Transplant 23:3256-3262

32. Evrard S, Delanaye P, Kamel S, Cristol JP, Cavalier E, SFBC, SN joined working group on vascular calcifications (2015) Vascular calcification: from pathophysiology to biomarkers. Clin Chim Acta. doi:10.1016/j.cca.2014.08.034

33. Van Campenhout A, Golledge J (2009) Osteoprotegerin, vascular calcification and atherosclerosis. Atherosclerosis 204:321-329 
34. Toffoli B, Pickering RJ, Tsorotes D et al (2011) Osteoprotegerin promotes vascular fibrosis via a TGF- $\beta 1$ autocrine loop. Atherosclerosis 218:61-68

35. Hofbauer LC, Shui C, Riggs BL et al (2001) Effects of immunosuppressants on receptor activator of NF-kappaB ligand and osteoprotegerin production by human osteoblastic and coronary artery smooth muscle cells. Biochem Biophys Res Commun 280:334-339

36. Sasaki N, Kusano E, Ando Y, Yano K, Tsuda E, Asano Y (2001) Glucocorticoid decreases circulating osteoprotegerin (OPG): possible mechanism for glucocorticoid induced osteoporosis. Nephrol Dial Transplant 16:479-482 